\title{
High Prevalence of Depressive Symptoms Among Ugandan Patients with Rheumatoid Arthritis
}

\author{
Felix Bongomin (1D ${ }^{1,2}$ \\ Barbra Natukunda' \\ Maria Sekimpi' \\ Ronald Olum (D) \\ Joseph Baruch Baluku (D) ${ }^{3,4}$ \\ Anthony Makhoba ${ }^{5,6}$ \\ Mark Kaddumukasa (D) \\ 'Department of Medicine, College of \\ Health Sciences, Makerere University, \\ Kampala, Uganda; ${ }^{2}$ Department of \\ Immunology and Medical Microbiology, \\ Gulu University Medical School, Gulu, \\ Uganda; ${ }^{3}$ Division of Pulmonology, \\ Mulago National Referral Hospital, \\ Kampala, Uganda; ${ }^{4}$ Directorate of \\ Programs, Mildmay Uganda, Wakiso, \\ Uganda; ${ }^{5}$ Department of Medicine, \\ St. Francis's Hospital- Nsambya, Kampala, \\ Uganda; ${ }^{6}$ Department of Medicine, \\ Mother Kevin Postgraduate Medical \\ School, Uganda Martyrs University, \\ Kampala, Uganda
}

Correspondence: Felix Bongomin Department of Medicine, College of Health Sciences, Makerere University, Kampala, Uganda

Tel +256 784-523-395

Email drbongomin@gmail.com
Background: There is a scarcity of data on the burden of depression among Ugandans with rheumatoid arthritis (RA) patients. We aimed to screen for symptoms of depression, their severity and associated factors among patients with RA in Uganda.

Patients and Methods: A descriptive, cross-sectional study was conducted between September and December 2020 at Mulago National Referral Hospital (MNRH) and Nsambya Hospital. Patients with RA were enrolled consecutively. Data on demographics, disease course and comorbidities and depression symptomatology were collected through an interviewer administered questionnaire. Symptoms of depression were screened for using the depression/anxiety dimension of the EuroQoL questionnaire.

Results: Forty-eight patients with a median age of 52 (IQR: 43.5-60.5) years were recruited in the study. The majority of the patients were female $(91.7 \%, n=44)$. Twenty-nine patients $(60.4 \%)$ had comorbidities with a median Charlson comorbidity score of 3 (IQR: 2-4). Overall, 70.8\% $(\mathrm{n}=34)$ had depressive symptoms. Patients attending MNRH were more likely to have depressive symptoms $(p=0.025)$. Significantly, patients with depressive symptoms were younger $(p=0.027)$, had lower health index value $(p<0.001)$, and lower overall self-reported health status $(\mathrm{p}=0.013)$. At binary logistic regression, patients at MNRH (crude odds ratio (COR): 4.32, 95\% confidence interval $(\mathrm{CI}): 1.16-16.15, \mathrm{P}=0.030$ ), patients aged $<52$ years (COR: 5.24, 95\% CI: 1.23-22.28, $\mathrm{P}=0.025$ ) and those with mild RA (COR: 5.71, 95\% CI: $1.15-28.35, \mathrm{P}=0.033)$ were significantly more likely to have depressive symptoms. Increase in age (COR: $0.94,95 \% \mathrm{CI}: 0.89-0.99, \mathrm{P}=0.025$ ), and high visual analogue score (COR: 0.94, 95\% CI: 0.89-0.99, $\mathrm{P}=0.013$ ) were protective.

Conclusion: Depressive symptoms were common among RA patients in Uganda. Routine screening, diagnosis and management of depression is recommended among young patients to improve quality of life and patient outcomes.

Keywords: rheumatoid arthritis, depression, ED-5D-5L, Uganda

\section{Introduction}

Rheumatoid arthritis (RA), a multi-systemic, chronic inflammatory disease characterized by symmetrical peripheral polyarthritis with or without extra-articular involvement is a debilitating autoimmune disease with an estimated prevalence ranging from 0.5 to $1 \%$ in developed countries. ${ }^{1}$ The burden of this progressive disease in developing countries is largely unknown.

RA is associated with a number of physical and mental health symptoms. ${ }^{2}$ The two most common mental health issues experienced by people living with RA are anxiety and depression. ${ }^{3}$ In 2013, a systematic review and meta-analysis of 72 studies reported a pooled prevalence of major depressive disorder of about $17 \%$ 
among 13,189 patients with RA. ${ }^{4}$ Depression in patients with RA is associated with frequent flare of symptoms, lower improvement in disease activity, progressive disability, poor quality of life and poor overall prognosis. ${ }^{5}$ A study in Poland found that $76 \%$ of RA patients had symptoms of depression. ${ }^{6}$ Depression in this study was significantly associated with professional inactivity, and positively correlated with pain, disease activity, and number of painful or swollen joints. ${ }^{6}$ In Kenya, $28.4 \%$ of RA patients were depressed, and patients with poor physical quality of health scores, poorer energy scores, emotional wellbeing and social functioning were significantly more likely to be depressed. ${ }^{7}$

The mechanism by which RA causes depression is poorly understood but is thought to be related with the ongoing inflammatory processes and pain associated with RA. ${ }^{5}$ This is supported by studies which show that inflammatory cytokines and acute phase reactants are elevated among patients with depressive symptoms and improvement of depressive symptoms on treatment with anti-inflammatory agents and RA disease modifying anti-rheumatic drugs (DMARDS). ${ }^{8}$

The anxiety/depression dimension of ED 5D 5L provides a simple and yet a reliable way of quickly screening for depressive symptoms among patients with RA. ${ }^{9}$ Despite depression being a treatable condition with a negative impact on RA progression and control, recent studies suggest that depression may be under-recognized and under-treated among patients with RA. ${ }^{3}$ In this study therefore, we aimed to screen for symptoms of depression among Ugandan patients with RA.

\section{Patients and Methods Study Design}

We conducted a clinical audit where we cross-sectionally surveyed our patients with RA attending two outpatient rheumatology clinics in Uganda between September and December 2020.

\section{Study Area}

The study was undertaken at Mulago National Referral Hospital (MNRH) and St. Francis's Hospital-Nsambya (SFHN) both of which are situated in, Kampala, the capital city of Uganda. MNRH is Uganda's largest public hospital. It is located at Mulago hill, 5 kilometers by road northeast of Kampala's central business district. Patients enrolled in the RA clinic at MNRH are attended to by specialists at the rheumatology clinic which runs once a week. SFHN is a faith-based not-for-profit hospital located on Nsambya hill, Makindye division, Kampala; 6 kilometers south-east of MNRH. Public hospitals in Uganda are sometimes faced with drug stock shortages which may affect care for RA patients as well.

\section{Study Population}

All patients aged 18 years or older with a confirmed diagnosis of RA diagnosed according to the EULAR/ACR diagnostic criteria regularly attending the clinic and presenting for care during the routine RA clinics at MNRH and SFNH were included. ${ }^{10}$ Patients with psychiatristdiagnosed co-morbid anxiety, depression and other mental illnesses were excluded.

\section{Data Collection}

Data were collected using semi-structured questionnaires administered by the treating physicians (the authors) during routine clinical care. Data were collected on the following parameters: (1) patient socio-demographic characteristics: age, gender, marital status, level of education, current employment status, monthly income and financial support; (2) Clinical diagnosis: duration of illness, self-reported disease severity, disease flares, and hospitalization; (3) Medication: DMARDs used, duration of therapy, source of DMARDs, monthly expenditure on DMARDs, satisfaction with treatment, concomitant use of herbal medication, adverse drug reactions; and (4) co-morbidities

\section{Patient-Reported Outcome Measure}

The EQ-5D-5L, consisting of 5 dimensions and 5 levels was administered to the participants. ${ }^{11}$ The 5 dimensions assessed were mobility, self-care, usual activities, pain/ discomfort, and anxiety/depression. Each dimension has five levels (no problems, slight problems, moderate problems, severe problems, extreme problems/unable to). Health state profile was generated from these dimensions and levels using Zimbabwean reference values. The Reference date was the day of the clinic visit. Overall selfrated health status was assessed using the visual analogue scale (VAS) on which the patient rates his/her perceived health from 0 (the worst imaginable health) to 100 (the best imaginable health).

Depressive symptoms were screened for and their severity classified using the EQ-5D-5L anxiety/depression dimension at five levels: $1=$ no, $2=$ mild, $3=$ moderate, 4 $=$ severe, and $5=$ extreme. $^{11}$ 


\section{Data Analysis}

All data analyses were performed using STATA 16.0 (StataCorp LLC, College Station, Texas, USA) and Microsoft Excel 2016. Categorical variables were presented as frequencies and percentages whereas numerical variables were summarised as median (interquartile range (IQR)) since they were not normally distributed. Normal distribution was assessed using Shapiro-Wilk test for normality. To assess for the factors associated with depression among patients with RA, chi-square test or Fisher's Exact test and Mann-Whitney $U$-test were used. A binary logistic regression was performed for all significant factors at bivariate analysis. A $\mathrm{P}<0.05$ was considered statistically significant.

\section{Ethical Considerations}

This study was approved by the School of Medicine Research Ethics Committee (SOMREC, reference number \#REC REF 2020-221) at Makerere University College of Health Sciences. The study was conducted according to the Declaration of Helsinki. All participants provided a written informed consent.

\section{Results}

\section{Socio-Demographic Characteristics}

A total of 48 patients with a median age of 52 years (IQR: 43.5-60.5 years) were recruited in the study (Table 1). The vast majority of the participants were female $(91.7 \%$, $\mathrm{n}=44)$. About one-third of the participants were married $(33.3 \%, n=15)$. The median monthly income was 100,000 Uganda shillings (UGX) (approximately 28 United States dollars) with $68.8 \%$ having informal employments. The patients had lived with RA for a median duration of 60 months (IQR: 24-120 months) from onset of symptoms and only 6 patients $(12.5 \%)$ had self-reported controlled disease by self-report. The median number of disease flares (in the past 3 months) and clinic visits (past 12 months) was 1 (IQR: 0-2) and 4 (IQR: 3-6) respectively. About half of the patients were on methotrexate only treatment $(47.9 \%)$ with a median duration on DMARDs treatment for 12 months (IQR: 4-36 months). Most patients got their DMARDs from private pharmacies and spent 120,000 UGX monthly on buying them (IQR: $60,000-150,000$ UGX). About 33.3\% $(n=16)$ of the patients described experiencing adverse effects to DMARDs and some $10.4 \% \quad(n=5)$ reported that DMARDs affected their activities. Twenty-nine patients
(60.4\%) had comorbidities with a median Charlson comorbidity score of 3 (IQR: $2-4)$. Up to $31.3 \%(n=15)$ of the patients reported low adherence to DMARDs. The median for health index score was 0.6 (IQR: 0.5-0.7) and 55 (IQR: 50-65) for overall self-reported health status.

\section{Prevalence and Factors Associated with Depressive Symptoms}

The prevalence of depressive symptoms was 70.8\% $(\mathrm{n}=34)$ among patients with RA (Table 2). About $27.1 \%$ and $25 \%$ of the patients had moderate and mild depressive symptoms, respectively (Figure 1). Depressive symptoms were significantly associated with the rheumatology clinic attended, age, health index value and overall self-rated health status at bivariate analysis (Table 2). Mulago Hospital significantly had higher number of RA patients with depressive symptoms compared to Nsambya Hospital $(p=0.025)$. The median age of RA patients with depressive symptoms was also significantly lower than those without depression (median: 46.5 vs 60.0 years, $p=0.015$ ). Similarly, patients aged $<50$ years were significantly more depressed compared to those aged $\geq 50$ years $(p=0.027)$. The health index value was significantly lower for patients with depressive symptoms compared to those without (median score: 0.6 vs $0.7, \mathrm{P}<0.001)$. The overall self-rated health status was also significantly lower in patients with depressive symptoms compared to those without (median: 50.0 vs 62.5, p=0.013). Sex, duration of illness, disease severity, comorbidities and adverse effects of DMARDS were not significantly associated with depressive symptoms.

At binary logistic regression (Table 3), patients at Mulago Hospital were four times more like to have depressive symptoms than those at Nsambya Hospital (crude odds ratio (COR): 4.32, 95\% confidence interval (CI): 1.16-16.15, $\mathrm{P}=0.030$ ). Increase in age (COR: 0.94, 95\% CI: $0.89-0.99$, $\mathrm{P}=0.025$ ) and VAS score (COR: 0.94, 95\% CI: 0.89-0.99, $\mathrm{p}=0.013)$ were also less likely associated with depressive symptoms. Patients aged $<52$ years were 5 times more likely to have depressive symptoms compared to their elderly counterparts. Patients with mild, moderate and severe disease were all more likely to have depressive symptoms however, the association was statistically significant for those with mild RA (COR: 5.71, 95\% CI: 1.15-28.35, p=0.033). 
Table I Characteristics of the Patients

\begin{tabular}{|c|c|c|}
\hline Variables & Frequency or Median & $\%$ or IQR \\
\hline \multicolumn{3}{|l|}{ Hospital } \\
\hline Mulago Hospital & 29 & 60.4 \\
\hline Nsambya Hospital & 19 & 39.6 \\
\hline \multicolumn{3}{|l|}{ Sex } \\
\hline Female & 44 & 91.7 \\
\hline Male & 4 & 8.3 \\
\hline Age; median (IQR) & 52 & $43.5-60.5$ \\
\hline$<52$ & 23 & 47.9 \\
\hline$\geq 52$ & 25 & 52.1 \\
\hline \multicolumn{3}{|l|}{ Marital status } \\
\hline Single & 16 & 33.3 \\
\hline Married & 15 & 33.3 \\
\hline Divorced & 6 & 12.5 \\
\hline Widow(er) & 11 & 22.9 \\
\hline \multicolumn{3}{|l|}{ Education level } \\
\hline Informal & 5 & 10.4 \\
\hline Primary & 14 & 29.2 \\
\hline Secondary & 10 & 20.8 \\
\hline Tertiary & 19 & 39.6 \\
\hline \multicolumn{3}{|l|}{ Employment status } \\
\hline Formal & 15 & 31.3 \\
\hline Informal & 33 & 68.8 \\
\hline Income; median (IQR), Uganda shillings & 100,000 & $50,000-450,000$ \\
\hline$<100,000$ & 4 & 26.7 \\
\hline$\geq 100,000$ & 11 & 73.3 \\
\hline \multicolumn{3}{|l|}{ Financial support from family } \\
\hline Yes & 36 & 75.0 \\
\hline No & 12 & 25.0 \\
\hline Duration of illness in months; median (IQR) & 60 & $24-120$ \\
\hline$\leq 1$ year & 23 & 47.9 \\
\hline$>$ I year & 25 & 52.1 \\
\hline \multicolumn{3}{|l|}{ Self-reported disease severity } \\
\hline Controlled & 6 & 12.5 \\
\hline Mild & 9 & 18.8 \\
\hline Moderate & 18 & 37.5 \\
\hline Severe & 11 & 22.9 \\
\hline Very severe & 4 & 8.3 \\
\hline Clinic visits in last 12 months & 4 & $3-6$ \\
\hline Disease flares in last 3 months & 1 & $0-2$ \\
\hline Hospital admissions in last 12 months & 0 & $0-0$ \\
\hline \multicolumn{3}{|l|}{ Regimen } \\
\hline Methotrexate alone & 23 & 47.9 \\
\hline Hydroxychloroquine alone & 8 & 16.7 \\
\hline Hydroxychloroquine + Methotrexate & 8 & 16.7 \\
\hline Methotrexate + Leflunomide & 6 & 12.5 \\
\hline
\end{tabular}

(Continued) 
Table I (Continued).

\begin{tabular}{|c|c|c|}
\hline Variables & Frequency or Median & $\%$ or IQR \\
\hline Hydroxychloroquine + Azathioprine & 2 & 4.2 \\
\hline Hydroxychloroquine + Methotrexate + Leflunomide & 1 & 2.1 \\
\hline Duration on DMARDS; median (IQR) & 12 & $4-36$ \\
\hline$\leq 48$ months & 26 & 57.8 \\
\hline$>48$ months & 19 & 42.2 \\
\hline \multicolumn{3}{|l|}{ Source of DMARDS } \\
\hline Nsambya Hospital & 14 & 29.2 \\
\hline Private pharmacy & 34 & 70.8 \\
\hline Monthly cost of DMARDS & 120,000 & $60,000-150,000$ \\
\hline \multicolumn{3}{|l|}{ Satisfaction with medical treatment } \\
\hline Yes & 40 & 83.3 \\
\hline No & 8 & 16.7 \\
\hline \multicolumn{3}{|l|}{ Herbal medicine used } \\
\hline Yes & 11 & 22.9 \\
\hline No & 37 & 77.1 \\
\hline \multicolumn{3}{|l|}{ Does DMARDS affect your daily activity? } \\
\hline Yes & 5 & 10.4 \\
\hline No & 43 & 89.6 \\
\hline \multicolumn{3}{|l|}{ Adverse drug reactions to DMARDS } \\
\hline Yes & 16 & 33.3 \\
\hline No & 32 & 66.7 \\
\hline \multicolumn{3}{|l|}{ Co-morbidities } \\
\hline Yes & 29 & 60.4 \\
\hline No & 19 & 39.6 \\
\hline Hypertension & 26 & 54.2 \\
\hline Diabetes & 3 & 6.3 \\
\hline Chronic Heart Failure & 2 & 4.2 \\
\hline Chronic Lung Disease & 1 & 2.1 \\
\hline HIV & I & 2.1 \\
\hline Coronary artery disease & 1 & 2.1 \\
\hline Charlson Comorbidity index & 3 & $2.0-4.0$ \\
\hline \multicolumn{3}{|l|}{ Adherence } \\
\hline High & 33 & 68.8 \\
\hline Low & 15 & 31.3 \\
\hline Health index value & 0.6 & $0.5-0.7$ \\
\hline Overall self-rated health status & 55 & $50-65$ \\
\hline
\end{tabular}

Abbreviations: HIV, human immunodeficiency virus; DMARDS, disease modifying anti-rheumatic drugs; IQR, inter-quartile range.

\section{Discussion}

Depression is a well-recognized and a common mental health issue in persons with RA and leads to worst health outcomes. ${ }^{12,13}$ In the present study, we report two major findings. Firstly, among Ugandan patients with RA, the prevalence of depressive symptoms was $70.8 \%$. This study adds to the existing body of literature and supports existence of a high prevalence of depressive symptoms among patients with RA, even in developing countries. This burden of suspected depression in RA is four times than that of the general population in Uganda, which stands at about $18 \%{ }^{14}$ and $2-6$ times the global burden 
Table 2 Prevalence and Factors Associated with Depressive Symptoms Among Patients with Rheumatoid Arthritis Among Patients at Mulago and Nsambya Hospitals

\begin{tabular}{|c|c|c|c|}
\hline \multirow[t]{2}{*}{ Variables } & \multicolumn{2}{|c|}{ Depressive Symptoms } & \multirow[t]{2}{*}{ p-value } \\
\hline & Yes & No & \\
\hline Overall & $34(70.8)$ & $14(29.2)$ & \\
\hline \multicolumn{4}{|l|}{ Hospital } \\
\hline Mulago Hospital & $24(82.8)$ & $5(17.2)$ & 0.025 \\
\hline Nsambya Hospital & $10(52.6)$ & $9(47.4)$ & \\
\hline \multicolumn{4}{|l|}{ Sex } \\
\hline Male & $2(50)$ & $2(50)$ & 0.569 \\
\hline Female & $32(72.7)$ & $12(27.3)$ & \\
\hline Age; mean (SD) & $46.5(35.0-58.0)$ & $60(52-65)$ & 0.015 \\
\hline$<50$ & $20(87)$ & $3(13)$ & 0.027 \\
\hline$\geq 50$ & $14(56)$ & II (44) & \\
\hline \multicolumn{4}{|l|}{ Marital status } \\
\hline Single & $13(81.3)$ & $3(18.8)$ & 0.721 \\
\hline Married & $10(66.7)$ & $5(33.3)$ & \\
\hline Divorced & $4(66.7)$ & $2(33.3)$ & \\
\hline Widow(ed) & $7(63.6)$ & $4(36.4)$ & \\
\hline \multicolumn{4}{|l|}{ Education level } \\
\hline Informal & $2(40)$ & $3(60)$ & $0.40 \mathrm{I}$ \\
\hline Primary & II (78.6) & $3(2 \mid .4)$ & \\
\hline Secondary & $8(80)$ & $2(20)$ & \\
\hline Tertiary & $13(68.4)$ & $6(31.6)$ & \\
\hline \multicolumn{4}{|l|}{ Employment status } \\
\hline Formal & $12(80)$ & $3(20)$ & 0.498 \\
\hline Informal & $22(66.7)$ & II (33.3) & \\
\hline Income; median (IQR) & $150,000(75,000-470,000)$ & $100,000(50,000-450,000)$ & 0.770 \\
\hline$<100,000$ & $3(75)$ & I (25) & 0.770 \\
\hline$\geq 100,000$ & $9(81.8)$ & $2(18.2)$ & \\
\hline \multicolumn{4}{|l|}{ Financial support from family } \\
\hline Yes & $25(69.4)$ & II (30.6) & 0.714 \\
\hline No & $9(75)$ & $3(25)$ & \\
\hline Duration of illness; median (IQR) & & $66(48-120)$ & 0.275 \\
\hline$\leq I$ year & I8 (78.3) & $5(2 \mid .7)$ & 0.278 \\
\hline$>$ I year & $16(64)$ & $9(36)$ & \\
\hline \multicolumn{4}{|l|}{ Disease severity } \\
\hline Controlled & $2(33.3)$ & $4(66.7)$ & 0.128 \\
\hline Mild & $5(55.6)$ & $4(44.4)$ & \\
\hline Moderate & $15(83.3)$ & $3(16.7)$ & \\
\hline Severe & $9(81.8)$ & $2(18.2)$ & \\
\hline Very severe & $3(75)$ & I (25) & \\
\hline Clinic visits in last 12 months & $4(3-6)$ & $4.5(3.0-6.0)$ & 0.845 \\
\hline Disease flares in last 3 months & $I(I-2)$ & $I(0-1)$ & 0.138 \\
\hline Hospital admissions in last 12 months & $0(0-1)$ & $0(0-0)$ & 0.083 \\
\hline
\end{tabular}

(Continued) 
Table 2 (Continued).

\begin{tabular}{|c|c|c|c|}
\hline \multirow[t]{2}{*}{ Variables } & \multicolumn{2}{|c|}{ Depressive Symptoms } & \multirow[t]{2}{*}{ p-value } \\
\hline & Yes & No & \\
\hline \multicolumn{4}{|l|}{ Family history of autoimmune diseases } \\
\hline Yes & $3(42.9)$ & $4(57.1)$ & 0.171 \\
\hline No & $31(75.6)$ & $10(24.4)$ & \\
\hline \multicolumn{4}{|l|}{ Regimen } \\
\hline Methotrexate & $17(73.9)$ & $6(26.1)$ & 0.573 \\
\hline Hydroxychloroquine & $7(87.5)$ & $\mathrm{I}(12.5)$ & \\
\hline Hydroxychloroquine + Methotrexate & $5(62.5)$ & $3(37.5)$ & \\
\hline Methotrexate + Leflunomide & $3(50)$ & $3(50)$ & \\
\hline Hydroxychloroquine + Azathioprine & $\mathrm{I}(50)$ & $\mathrm{I}(50)$ & \\
\hline Hydroxychloroquine + Methotrexate + Leflunomide & $I(100)$ & $0(0)$ & \\
\hline Duration on DMARDS; median (IQR) & $12(4-36)$ & & 0.867 \\
\hline$\leq 48$ months & $19(73.1)$ & $7(26.9)$ & 0.964 \\
\hline$>48$ months & $14(73.7)$ & $5(26.3)$ & \\
\hline \multicolumn{4}{|l|}{ Source of DMARDS } \\
\hline Nsambya Hospital & $8(57.1)$ & $6(42.9)$ & 0.181 \\
\hline Private pharmacy & $26(76.5)$ & $8(23.5)$ & \\
\hline Monthly cost of DMARDS & $110,000(33,600-148,000)$ & $135,000(97,000-190,000)$ & 0.154 \\
\hline \multicolumn{4}{|l|}{ Satisfaction with medical treatment } \\
\hline Yes & $27(67.5)$ & $13(32.5)$ & 0.407 \\
\hline No & $7(87.5)$ & I (I2.5) & \\
\hline \multicolumn{4}{|l|}{ Adverse drug reactions to DMARDS } \\
\hline Yes & $13(8 \mid .3)$ & $3(18.8)$ & 0.328 \\
\hline No & $21(65.6)$ & II (34.4) & \\
\hline \multicolumn{4}{|l|}{ Co-morbidities } \\
\hline Yes & $14(60.9)$ & $9(39.1)$ & 0.145 \\
\hline No & $20(80)$ & $5(20)$ & \\
\hline Charlson Comorbidity index & $2.5(2-4)$ & $3(3-4)$ & 0.353 \\
\hline \multicolumn{4}{|l|}{ Adherence } \\
\hline High & $22(66.7)$ & II (33.3) & 0.498 \\
\hline Low & $12(80)$ & $3(20)$ & \\
\hline Index value & $0.6(0.4-0.7)$ & $0.7(0.7-0.8)$ & $<0.001$ \\
\hline Visual analogue scale & $50(50-60)$ & $62.5(50-75)$ & 0.013 \\
\hline
\end{tabular}

Abbreviations: DMARDS; disease modifying anti-rheumatic drugs; IQR, inter-quartile range.

of depression in patients with RA, which ranges between $12 \%$ and $44 \%{ }^{4}$ In the UK, around $30 \%$ of RA patients developed depression within 5 years of the RA diagnosis. $^{15}$ In Egypt, $45 \%$ of RA patients had depression. ${ }^{16}$ In Kenya, $28.5 \%$ of patients with RA had depression. ${ }^{7}$ The observed difference could be because of the differences in the study tools, sample sizes, comorbidities and social circumstances. ${ }^{4,5,17}$
Secondly, in our study, RA patients with suspected depression were much younger and had poorer quality of life compared to their non-depressed counterparts. Consistently, published literature suggests that low socioeconomic status, gender, age, race/ethnicity, joint surgery, steroid use, functional limitation, pain and poor clinical status have a strong association with depression among persons with RA. ${ }^{8,16}$ We did not observe any gender 


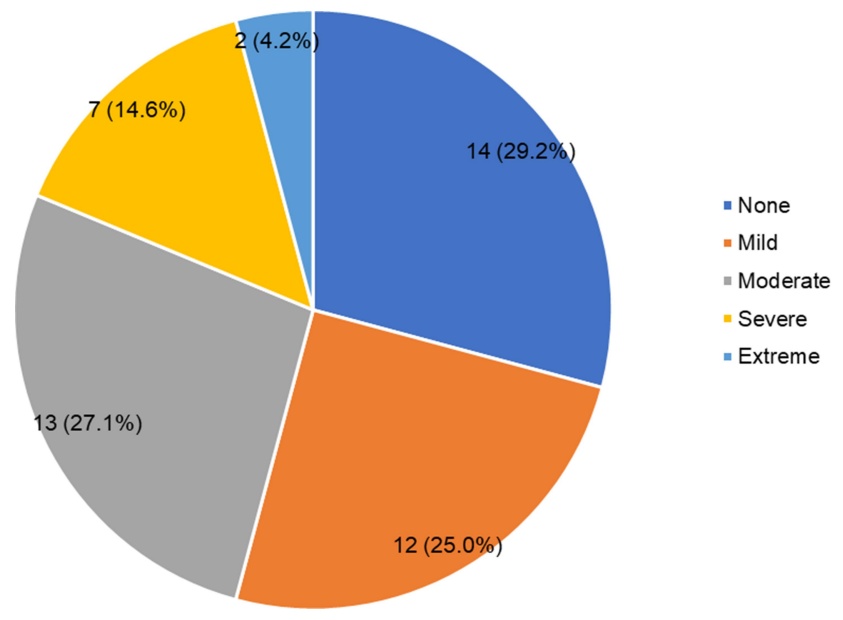

Figure I Prevalence and severity of depressive symptoms among patients with rheumatoid arthritis in Uganda.

differences in those with suspected depression and those without depressive symptoms among our participants. This is contrast with previously published studies showing that women with RA are more prone depression. ${ }^{4}$ However, a study in Poland among 104 RA patients also found no significant difference in depression between males and females. $^{6}$

We observed a significant difference in the prevalence of depressive symptoms across the 2 centres with patients attending MNRH having a higher prevalence. This could be due to the majority of patients attending MNRH being more ill, lack access to essential DMARDs and being

Table 3 A Binary Logistic Regression Showing Factors Associated with Depressive Symptoms Among Patients with RA

\begin{tabular}{|c|c|c|c|}
\hline Variables & $\begin{array}{c}\text { Crude Odds } \\
\text { Ratio }\end{array}$ & $95 \% \mathrm{Cl}$ & P-value \\
\hline \multicolumn{4}{|l|}{ Hospital } \\
\hline Nsambya Hospital & 1.00 & & \\
\hline Mulago Hospital & 4.32 & $1.16-16.15$ & 0.030 \\
\hline Age, years & 0.94 & $0.89-0.99$ & 0.025 \\
\hline \multicolumn{4}{|l|}{ Age category, years } \\
\hline$\geq 52$ & 1.00 & & \\
\hline$<52$ & 5.24 & $1.23-22.28$ & 0.025 \\
\hline \multicolumn{4}{|l|}{$\begin{array}{l}\text { Self-reported disease } \\
\text { severity }\end{array}$} \\
\hline Controlled & 1.00 & & \\
\hline Mild & 5.71 & I.15-28.35 & 0.033 \\
\hline Moderate & 5.14 & $0.82-32.3$ & 0.081 \\
\hline Severe & 3.43 & $0.29-40.95$ & 0.33 \\
\hline Visual analogue scale & 0.94 & $0.89-0.99$ & 0.013 \\
\hline
\end{tabular}

Abbreviation: $\mathrm{Cl}$, confidence interval. relatively of low socioeconomic status. Also, Mulago receives referral from all over Uganda. Some of these patients are often polymorbid with other complications/ comorbidities and suffer more recurrent flares compared to patients attending SFHN who are mainly from around Kampala and are of higher socio-economic status.

It's unclear whether depression in people with RA are a result of their physical symptoms, or if depression is yet another symptom caused by the chronic, systemic inflammation of RA. ${ }^{13}$ Studies have demonstrated that systemic inflammation in RA patients leads to an increased concentration of pro-inflammatory cytokines and acute-phase reactants, which in-turn have been associated with development of depression in RA patients. Similarly, depression increases also lead to an increase in serum pro-inflammatory cytokines in RA patients. ${ }^{8}$

From a clinical standpoint, improved detection through active screening and treatment of patients with both RA and depression are important. ${ }^{15}$ This is because, focusing only on RA, without addressing mental health issues like anxiety or depression, can lead to lower quality of life and poor RA treatment outcomes. Provision of equal priority to mental and physical health problems by treating rheumatologists and improved continuity of care could help disclosure of mood concerns. Facilitation of access to psychological therapies could improve outcomes for both mental and physical health problems. ${ }^{3}$ Lifestyle changes, therapy, and appropriate depression treatment should be offered to the affected patients.

Important complications of untreated depression in patients with RA, includes exacerbation of symptoms, greater risk of cardiovascular disease, economic decline, loss of productivity, and sexual dysfunction, resulting to a significant morbidity and mortality. ${ }^{8}$

Our study is not without limitations. Significantly, the small sample size utilized in this study should be taken into consideration while interpreting the findings and inferences of the study. The small sample size is owed to the relatively low number of RA patients enrolled in care in Uganda and the short duration of the study period. We did not also assess pain itself as a symptom which is an important predictor of depression in patients with RA. In addition, we did not evaluate the use of steroids which may cause drug-induced depression in large doses. ${ }^{18}$ Clinical diagnosis of major depressive disorder requires either psychiatric interviews or the mini- neuropsychiatric interview. 


\section{Conclusion}

In this study, a significant proportion of RA patients in Uganda have comorbid depressive symptoms. Optimal care for RA patients therefore requires routine psychiatric assessment and management. More research into the etiology, morbidity, and mortality associated with depression in RA patients in Ugandan context is proposed. Studies assessing the healthcare burden and the socio-economic impact of depression in RA patients in Uganda are recommended.

\section{Data Sharing Statement}

Data are available upon reasonable request from the corresponding author.

\section{Acknowledgment}

Mark Kaddumukasa is supported by a grant from the National Institutes Health (K43TW010401) National Institute of Neurological Disorders and Stroke and Fogarty International Center (FIC). Felix Bongomin is partially supported by the Fogarty International Centre of the National Institutes of Health under Award Number D43 TW011401. The content is solely the responsibility of the authors and does not necessarily represent the official views of the National Institutes of Health.

\section{Author Contributions}

All authors made substantial contributions to conception and design, acquisition of data, or analysis and interpretation of data; took part in drafting the article or revising it critically for important intellectual content; agreed to submit to the current journal; gave final approval of the version to be published; and agree to be accountable for all aspects of the work.

\section{Disclosure}

The authors have declared no conflicts of interest for this work.

\section{References}

1. Shapira Y, Agmon-Levin N, Shoenfeld Y. Geoepidemiology of autoimmune rheumatic diseases. Nat Rev Rheumatol. 2010;6(8):468-476. doi:10.1038/nrrheum.2010.86
2. Crowson CS, Matteson EL, Myasoedova E, et al. The lifetime risk of adult-onset rheumatoid arthritis and other inflammatory autoimmune rheumatic diseases. Arthritis Rheum. 2011;63(3):633-639. doi:10.1002/art.30155

3. Machin A, Hider S, Dale N, Chew-Graham C. Improving recognition of anxiety and depression in rheumatoid arthritis: a qualitative study in a community clinic. Br J Gen Pract. 2017;67(661):e531-e537. doi:10.3399/bjgp17X691877

4. Matcham F, Rayner L, Steer S, Hotopf M. The prevalence of depression in rheumatoid arthritis: a systematic review and meta-analysis. Rheumatol. 2013;52(12):2136-2148. doi:10.1093/rheumatology/ ket169

5. Euesden J, Matcham F, Hotopf M, et al. The relationship between mental health, disease severity, and genetic risk for depression in early rheumatoid arthritis. Psychosom Med. 2017;79(6):638-645. doi:10.1097/PSY.0000000000000462

6. Kwiatkowska B, Kłak A, Maślińska M, Mańczak M, Raciborski F. Factors of depression among patients with rheumatoid arthritis. Reumatologia/Rheumatology. 2018;56(4):219-227. doi:10.5114/ reum.2018.77973

7. Doshi S, Go O, Ogola E. Depression and its association with disease activity and quality of life in patients with rheumatoid arthritis at the Kenyatta National Hospital. Afr J Rheumatol. 2020;8(1):15-21.

8. Margaretten M, Julian L, Katz P, Yelin E. Depression in patients with rheumatoid arthritis: description, causes and mechanisms. Int $J$ Clin Rheumtol. 2011;6(6):617-623. doi:10.2217/ijr.11.62

9. Katchamart W, Narongroeknawin P, Chanapai W, Thaweeratthakul P. Health-related quality of life in patients with rheumatoid arthritis. BMC Rheumatol. 2019;3(1):34. doi:10.1186/s41927-019-0080-9

10. Aringer M, Costenbader K, Daikh D, et al. 2019 European League Against Rheumatism/American College of Rheumatology classification criteria for systemic lupus erythematosus. Ann Rheum Dis. 2019;78(9):1151-1159. doi:10.1136/annrheumdis-2018-214819

11. EuroQol Group. EuroQol - a new facility for the measurement of health-related quality of life. Health Policy (New York). 1990;16 (3):199-208. doi:10.1016/0168-8510(90)90421-9

12. Nerurkar L, Siebert S, McInnes IB, Cavanagh J. Rheumatoid arthritis and depression: an inflammatory perspective. Lancet Psychiatry. 2019;6(2):164-173. doi:10.1016/S2215-0366(18)30255-4

13. Vallerand IA, Patten SB, Barnabe C. Depression and the risk of rheumatoid arthritis. Curr Opin Rheumatol. 2019;31(3):279-284. doi:10.1097/BOR.0000000000000597

14. Ovuga E, Boardman J, Wasserman D. The prevalence of depression in two districts of Uganda. Soc Psychiatry Psychiatr Epidemiol. 2005;40(6):439-445. doi:10.1007/s00127-005-0915-0

15. Jacob L, Rockel T, Kostev K. Depression risk in patients with rheumatoid arthritis in the United Kingdom. Rheumatol Ther. 2017;4(1):195-200. doi:10.1007/s40744-017-0058-2

16. ElSherbiny DA, ElSayed Saad W. Depression in rheumatoid arthritis patients: screening for a frequent yet underestimated comorbidity. Egypt Rheumatol. 2020;42(2):89-93. doi:10.1016/j.ejr.2019.07.002

17. Covic T, Cumming SR, Pallant JF, et al. Depression and anxiety in patients with rheumatoid arthritis: prevalence rates based on a comparison of the Depression, Anxiety and Stress Scale (DASS) and the hospital, Anxiety and Depression Scale (HADS). BMC Psychiatry. 2012;12:12. doi:10.1186/1471-244X-12-6

18. Wada K, Yamada N, Sato T, et al. Corticosteroid-induced psychotic and mood disorders: diagnosis defined by DSM-IV and clinical pictures. Psychosomatics. 2001;42(6):461-466. doi:10.1176/appi. psy.42.6.461 


\section{Publish your work in this journal}

Open Access Rheumatology Research and Reviews is an international, peer-reviewed, open access journal publishing original research, reports, editorials, reviews and commentaries on all aspects of clinical and experimental rheumatology in the clinic and laboratory including the following topics: Pathology, pathophysiology of rheumatological diseases; Investigation, treatment and management

Submit your manuscript here: https://www.dovepress.com/open-access-rheumatology-research-and-reviews-journal of rheumatological diseases; Clinical trials and novel pharmacological approaches for the treatment of rheumatological disorders. The manuscript management system is completely online and includes a very quick and fair peer-review system, which is all easy to use. Visit http://www.dovepress.com/testimonials.php to read real quotes from published authors. 